(Forthcoming in Kiverstein, J. \& Wheeler, M., Heidegger and Cognitive Science, New York: Palgrave)

\title{
Context-switching and responsiveness to real relevance
}

\author{
Erik Rietveld \\ Fellow in Philosophy \\ Harvard University \\ Department of Philosophy \\ Emerson Hall \\ Cambridge, MA 01238 \\ USA \\ rietveld@fas.harvard.edu \\ d.w.rietveld@amc.uva.nl
}

\section{Introduction}

Our everyday activities unfold in situations that offer a multiplicity of possibilities for action. While typing this text, the apple on the right side of my laptop affords eating, my e-mail checking, and the glass of water drinking from it. Every now and then I unreflectively switch from typing to eating or drinking and back to typing again. A relevant possibility for action is embedded in a field of other soliciting possibilities for action (Rietveld, 2008a/b). Michael Wheeler and Hubert Dreyfus have an interesting debate on the important issue of cognition in context. They both take a naturalistic and 
broadly Heideggerian approach to the problem of adequate sensitivity to contextdependent relevance (the frame-problem) ${ }^{1}$ Their debate focuses on such sensitivity in episodes of online intelligence (Wheeler, 2005, p. 252, p. 280), typing for instance. They agree that a central phenomenon to be understood is how one switches from one context to another by being responsive to what is relevant in a given situation. In a recent paper Wheeler (2008, p. 346) has replied to the concerns that Dreyfus (2008) has raised about Wheeler's (2005) representationalism on these matters.

Wheeler, who had earlier (2005) positioned himself as a fan of representations, now admits that the non-representational mechanism of continuous reciprocal causation $(\mathrm{CRC})^{2}$ is 'ontologically more basic' $(2008$, p. 346) than even action-oriented representations (AOR). The reason he mentions is the following:

'Since CRC plays a critical role in dissolving the inter-context frame problem, but action-oriented representations play no equivalent role, there is a clear sense in which CRC is the ontologically more basic phenomenon.' (Wheeler, 2008, p. 346, my italics).

So Wheeler and Dreyfus agree that it is a non-representational process, namely continuous reciprocal causation, that is the mechanistic basis of the phenomenon of context switching, which, in turn, is crucial for online intelligence.

Dreyfus plausibly describes this phenomenon of switching or changing contexts in terms of being solicited by an affordance or situation on the background of one's field of perception and action: 
'How do we sense when a situation on the horizon has become relevant to our current task? When Merleau-Ponty describes the phenomenon, he speaks of one's attention being drawn by an affordance on the margin of one's current experience.' (Dreyfus, 2008, p. 359).

Dreyfus adds:

'As I cope with a specific task in a specific situation, other situations that have in the past been relevant are right now present on the horizon of my experience as potentially (not merely possibly) relevant to my current situation.' (Dreyfus, 2008, p. 359, my italics).

Wheeler (2008, p. 344) agrees both with Dreyfus' description of this phenomenon ${ }^{3}$ and with Dreyfus' suggestion that the mechanical basis of this type of attunement to situational relevance should be understood in terms of continuous reciprocal causation (CRC), for instance Freeman's (2000a) neurodynamic model as described by Dreyfus $(2008){ }^{4}$

Although Wheeler now seems to be no longer a fan of representations regarding this central problem of online intelligence, he (2008, p. 346) is still ambivalent about something else, namely about the power of continuous reciprocal causation for dissolving the frame problem. It is in part this ambivalence that motivates this paper of mine. Wheeler writes that he still has a real disagreement with Dreyfus, because Dreyfus thinks that 
'it's CRC that provides a causal dissolution of the intra-context frame problem and not 'just' the inter-context version [of the frame problem]' (Wheeler, 2008, p. $345)$.

Wheeler, however, holds on to his recently introduced distinction ${ }^{5}$ between 'intra-contex' and 'inter-contex' sensitivity to relevance and writes:

'If I am ambivalent about anything here, it's about whether CRC or situated special-purpose adaptive coupling is ontologically more basic. [...T]his is where the real disagreement between Dreyfus and me lies [...]' (Wheeler, 2008, p. 346).

Notwithstanding this ambivalence, Wheeler (2008, p. 346) accepts implicitly that in the case of what he calls 'inter-context' sensitivity to relevance CRC is 'ontologically more basic', that is to say, more basic for dissolving the frame problem (Wheeler, 2008, p. 346), than 'situated special-purpose adaptive coupling' (henceforth SPAC) because it is its mechanistic basis:

'CRC is the causal-structural basis of fluid and flexible context-switching.' (Wheeler, 2008, p. 346).

The first aim of this paper is to show that there is no basis for Wheeler's ambivalence. Given 1) the fact he accepts that $\mathrm{CRC}$ is more basic for dissolving the frame problem than SPAC when the full situational context is taken into account by the individual (that is to say in the case of 'inter-context' sensitivity to relevance), and 2) my 
observation (see section 6 below) that what he calls 'intra-context' sensitivity to relevance is a sensitivity to real relevance only when the full particular or broad situational context is taken into account, he should accept that in the 'intra-context' case, too, $\mathrm{CRC}$ is more basic for dissolving the frame problem than SPAC. Adequate sensitivity to context-dependent relevance cannot neglect the full situational context.

The second aim of this paper is to show that the fact that CRC is the crucial causal mechanism for explaining sensitivity to real relevance, does not imply that Heideggerian cognitive science should study the phenomenon of online cognition only by means of the methods from neurodynamics. On the contrary, there is a lot to be learned about the central phenomena (such as responsiveness to relevant affordances) by treating the insights from various disciplines (for example cognitive neuroscience, neurodynamics, emotion psychology, phenomenology) as complementary. I will illustrate this methodological point by a discussion of a neurological disorder.

The third aim is to improve our understanding of background coping, a Heideggerian concept that plays an important role in the Wheeler-Dreyfus debate (in particular in Wheeler, 2008). The two types of online cognition Wheeler and Dreyfus distinguish, ready-to-hand and unready-to-hand modes of interaction with the world, are both dependent on background coping (Dreyfus, 2008; Wheeler, 2008). ${ }^{6}$ Although I will take phenomenological philosophy as my starting point with respect to background coping, I will focus on a level of analysis in between the phenomenological and neural levels, which I will here refer to as the psychological level of analysis.

I will start with the latter (section 2). In sections 3-5 I will discuss the neurological condition of utilization behavior. I will return to the Dreyfus-Wheeler debate and Wheeler's ambivalence in section 6. 


\section{Online cognition and background coping}

Much is still unknown about the way in which know-how works in the familiar situations of everyday life. We have seen above that the notion of affordances is helpful for improving this understanding (Gibson, 1979; Michaels, 2003; Chemero, 2003). Affordances are in this paper understood broadly, namely as an organism's possibilities for action provided by the environment. However, what I would like to focus on is the individual's responsiveness to affordances in some situation. Part of the phenomenology of such responsiveness is that perceived affordances are not mere possibilities for action but are experienced as bodily potentiating and/or having affective allure (Rietveld, 2008 b). ${ }^{7}$ Dreyfus and Kelly (2007, p. 52) describe the phenomenology of responsiveness to affordances as 'experience in which the world solicits a certain kind of activity'. Often we simply respond skillfully to affordances in online activity. I have argued elsewhere (Rietveld, 2008a) that for understanding such episodes of unreflective action, it is crucial that our responsiveness to affordances is concernful, in the sense that it takes into account what matters to us; our current needs, interests and preferences. We normally take for granted that we are not responsive to all affordances, but primarily to relevant

affordances for us. ${ }^{8}$ I will use the term solicitations (Dreyfus \& Kelly, 2007) as a synonym for the relevant affordances that we are responsive to.

We have seen in the introduction that for understanding how we switch unreflectively from doing one thing to doing another, it is important that we can be affected by affordances on the horizon (Dreyfus, 2007c; Dreyfus, 2008; Rietveld, 2008a; Rietveld, 2004). Moreover, phenomenological analysis suggests that it makes sense to say that we are situated in and bodily responsive to a field of relevant affordances 
(Rietveld, 2008b). This field is made up of a figure-affordance we are currently directed at and responding to, and a multiplicity of more marginally ${ }^{9}$ present ground-affordances that solicit us as well.

Although Walter Freeman (2000a/b) emphasizes the importance of emotion for intentional action, Wheeler $(2005 ; 2008)$ and Dreyfus (2008) have largely ignored this in their discussion. Given its link with the debated issue of background coping (Dreyfus, 2008; Wheeler, 2008, pp. 343-46), it is worth briefly making explicit how emotion could fit in. Let me explain.

For Dreyfus and Kelly (2007) solicitations are not merely perceived possibilities that reflect what one could or could not do. For them, the demand character (what the thing or event is inciting or ordering, Frijda, 2007) is intrinsic to the experience of a relevant affordance. The phenomenology of responsiveness to affordances in absorbed coping suggests that the individual feels immediately attracted or drawn to act in a certain way (Dreyfus \& Kelly, 2007, p. 52). According to Dreyfus (2008; cf. Merleau-Ponty, 2002/1945, p. 78), his or her activity is immediately summoned by the situation.

One does not just see what the situation allows one to do without actually arousing one's action readiness but, rather, one gets bodily ready to act. I have suggested (Rietveld, 2008b) that at the psychological level of analysis we can understand this getting bodily set to respond to the situation as a relevance-related change in the readiness of coping skills. ${ }^{10}$ As such the phenomenon of being drawn by a solicitation is an emotional perturbation in Frijda's (1986) sense. According to Frijda (2010) occurrent motive states are crucial for understanding what causes unreflective actions. Occurrent motive states are states of action readiness or action tendencies that are generated as a reaction to objects or events that are relevant to the individual's concerns (Frijda, 2010). 
These relevance-related embodied 'states of action readiness [...] flexibly motivate flexible actions' (Frijda, 2007, p. 115). He makes the following important observation:

'Emotions should not be primarily understood as reactions. They are best viewed as modulations of a prevailing background of continuous engagement with the environment.' (Frijda, 2007, p. 38).

Frijda's eye for the background of continuous bodily engagement with the world dovetails nicely with my current effort to call attention to the importance of not only relevant figure-affordances but also ground-affordances, that is to relevant affordances on the horizon.

In a discussion of background coping Wrathall (2000, p. 113) claims convincingly that

'Heidegger believes that if we want to understand what ordinarily generates intentional states, it is the readinesses, not the abilities, which are determinative.' (Wrathall, 2000, p. 113). ${ }^{11}$

Dreyfus' (2000) response to Wrathall's (2000) ideas on background coping suggests that Dreyfus will be able to accept a crucial role for these readinesses of coping skills:

'[I]t is only after reading Wrathall's chapter that I see that the phenomenon of readiness $[\ldots]$ solves the problem of finding something that is not an activity but is more active than a capacity. Our global or circumspective readiness to 
act appropriately makes intentional comportment possible but it is not itself a kind of comportment. Rather, readiness is the $[\ldots]$ root of intentional comportment [...]' (Dreyfus, 2000, p. 339).

Dreyfus clearly accepts a crucial role for readiness of coping skills in background coping. This phenomenon of readiness has a position in between capacity and overt action ('activity'). ${ }^{12}$

So one way to understand what Dreyfus (2008) calls 'background coping' is by keeping in mind that (at the psychological level of analysis at least) there is something in between overt action and a capacity: readinesses of coping skills (cf. Frijda, 2007). Thanks to the 'the intentional arc' (Merleau-Ponty, 2002/1945, Dreyfus, 2008) these readinesses are motivated from without in the sense that perceived relevant affordances are able to generate bodily action readinesses (Rietveld, 2008b). It is our bodily responsiveness to the 'summons' of ground affordances that makes understandable how our gaze can be attracted by a possibility for action that is unrelated to our current task yet significant (and sometimes even more significant than it). Generation of action readinesses in response to affordances present can occur in parallel to the individual's already being engaged in some overt activity. For instance, while typing this sentence the cup of coffee and cookies on the right side of my keyboard may simultaneously generate states of bodily action readiness.

Thanks to earlier learning and experience, which have shaped our coping skills and sensitivity to relevant affordances, we can here and now be moved towards improvement of our situation by simply being responsive to our particular field of relevant affordances (Rietveld, 2008c). This is a situated kind normativity, namely the 
normative aspect of embodied cognition in skillful unreflective action. As far as onlineintelligence is concerned, it is this phenomenon of adequately being moved to improve things, and not context switching by itself (so without taking the normative aspect of online intelligence into consideration), that is in urgent need of interdisciplinary explanation, including causal explanation.

\section{Utilization behavior}

In the neurological condition utilization behavior (UB) (Lhermitte, 1983) such immediate responsiveness to affordances has lost its sensitivity to the full particular situation. The French neurologist Lhermitte coined the term utilization behavior in the early 1980s. It describes the phenomenon that patients with a lesion of the frontal lobe (and/or of interconnected subcortical structures) demonstrate an exaggerated dependency on the environment in guiding their behavior. Patients with utilization behavior grasp and use familiar objects when they see them, neglecting their current situational irrelevance (Archibald et al., 2001; Boccardi et al., 2002; Eslinger, 2002). Such a UB-patient may, for example, put on a pair of glasses even though nothing is wrong with his eyes. Or upon seeing a bed he may start to undress, although this bed is in someone else's house. A light switch in his visual field may make him turn the light on and of continuously.

By way of contrast, UB sheds some light on our normal relationship with the world and use-objects in particular. It confirms Merleau-Ponty's (2002/1945) observation that the objects in our environment do not leave us cold, but affect us in striking ways. In utilization behavior such immediate responsiveness to affordances no longer takes the 
individual's concerns into account. Interestingly, these patients respond to irrelevant affordances (Rietveld, 2008b), which results in inappropriate actions. UB-patients show behavior that is technically correct, but inadequate given their personal needs, as well as inappropriate given the social norms of their socio-cultural environment (Archibald et al., 2001; Eslinger, 2002). An important characteristic of UB-patients is that they are not emotionally distressed about their responses to irrelevant affordances; they do not seem to care about the inappropriateness of their behavior (Rietveld, 2008b, chapter 6).

These patients have an acquired brain lesion. The plausible and broadly accepted hypothesis for UB is that at the neural level the (lateral premotor) ${ }^{13}$ system that generates stimulus-driven or externally-driven motor control has been disinhibited as a result of a lesion of the (medial premotor) system that generates internally-driven motor control (Goldberg, 1985, Archibald et al., 2001, Boccardi et al., 2002, Eslinger, 2002). Due to this lesion of the medial network, the patients' capacity for endogeneously-driven behavior is reduced (Eslinger, 2002). Some other terms for endogeneously-driven behavior are: self-generated (Levy \& Dubois, 2006), motivated (Tekin \& Cummings, 2002), internally-driven (Eslinger, 2002), or voluntary (Levy \& Dubois, 2006) behavior.

According to Paul Eslinger, in normal behavioral regulation the somewhat vague notions of internally-driven motor control or endogeneously-driven behavior refer to a poorly understood complex of "mechanisms that crisscross perception, goal-directed behavior, action knowledge, social cognition, and emotion' (Eslinger, personal communication d.d. January 2, 2006; cf. Paus, 2001).

It is informative that a severe loss of both endogeneously and externally guided action can be encountered in another neurological condition, akinetic mutism (Cairns et al., 1941; Devinsky et al., 1995; Rietveld, 2008b). These patients neither speak nor act; they 
lack initiative. Patients with utilization behavior and akinetic mutism have two important characteristics in common: a reduced responsiveness to really relevant affordances (because they respond respectively to irrelevant affordances or not at all) and a lack of emotional distress about this deficit.

An integration and accumulation of insights from philosophy, phenomenology, psychology and cognitive neuroscience could generate a better understanding of how it is possible that humans or animals are responsive to relevant affordances and generate adequate behavior accordingly. I will illustrate this by a more detailed discussion of utilization behavior.

\subsection{Characteristics of utilization behavior}

What is the full range of characteristics of utilization behavior that we are trying to understand by means of the medial-system hypothesis (which states that at the neural level a lesion of the medial system for internally-driven motor control disinhibits the stimulus-driven lateral system)? The core characteristics of utilization behavior as they arise from the literature seem to be the following. The patients needlessly, 'without any internal motivation' (Lhermitte, 1983, p. 253), and often inappropriately grasp and use objects when they see them, even when explicitly told not to do so (Lhermitte, 1983; Shallice et al., 1989). Moreover, they are not concerned or distressed about the fact that they are acting inappropriately (Lhermitte et al., 1986; Lhermitte, 1983, 1986; Eslinger, 2002; Boccardi et al., 2002). This characteristic of lack of distress is unfortunately often not tested nor reported in a standardized way in the literature. 
UB-patients are sensitive to only a part of the context. As mentioned above a UBpatient may, for example, start to undress upon seeing a bed, even if this bed is in someone else's house (Lhermitte, 1986). Or he grasps and eats the apple on the desk in the test room, even though it is the examiner's apple (Boccardi et al., 2002). Moreover, for the patient it would probably not make a difference if he or she had just eaten one or

two during lunch. ${ }^{14}$ Familiar objects are used more often than unfamiliar objects (Rudd et al., 1998). As mentioned above, these complex behavioral episodes have the important characteristic that they are instrumentally adequate, but at the same time inappropriate given the concrete personal and social context (Archibald et al., 2001; Eslinger, 2002). The patients do not restrain or stop purposeless or inappropriate actions (Lhermitte et al., 1986, p. 332). On the one hand, UB-patients seem to have retained a form of selfcorrection as far as the generation of an instrumentally adequate action is concerned (the action performed is technically correct - the apple is grasped in the way we would grasp it - and therefore task-directed in that limited sense). On the other hand, strangely enough, UB-patients show lost self-correction or self-criticism regarding the broader purposelessness or inappropriateness of their behavior (Lhermitte et al., 1986; Lhermitte, 1986).

Let us now consider the neural mechanisms underlying UB in greater detail.

\subsection{Lesions and neural mechanisms of UB}

The most common lesions of UB patients are bilatera ${ }^{15}$ lesions of the medial frontal cortex (anterior cingulate cortex (ACC), pre-supplementary motor area (pre-SMA) and supplementary motor area (SMA)) and/or interconnected subcortical structures: the 
striatum and the anterior and medial nuclei of the thalamus (Archibald et al., 2001, pp. 126-127). The striatum consists of the caudate nucleus and the putamen. The striatum is part of the basal ganglia. In what follows I will pay more attention to the role of the caudate nucleus than to that of the putamen because damage to the caudate nucleus is encountered more frequently in patients with utilization behavior (Archibald et al, 2001). Note that I will sometimes write (pre-)SMA because, unfortunately, in the years in which most of the research on UB was conducted it was not yet common to distinguish between SMA and pre-SMA ('SMA' was used for both).

As mentioned above, in order to explain the neurological mechanisms of $U B$, it is useful to make a distinction between the functionality of the lateral premotor system (parietal cortex, lateral premotor cortex, cerebellum, thalamus) and that of the medial premotor system (ACC, (pre-)SMA, basal ganglia, thalamus) (Goldberg, 1985). ${ }^{16}$ Most of the recent accounts of the neural mechanisms of UB use Goldberg's framework (Archibald et al., 2001; Eslinger, 2002). The hypothesis in this body of literature with respect to the mechanisms underlying UB can be summarized as follows: UB is the result of a loss of inhibition at the neural level, because a lesion of the medial system disinhibits the lateral system. More specifically, the authors observe an imbalance between the medial premotor system and the lateral premotor system. A loss of internally driven motor control (Archibald et al. 2001, p. 129; Eslinger, 2002, p. 275) and of modulation of the lateral premotor system is presumably the result of this lesion of the medial premotor system.

To sum up, selective (and generally bilateral) lesions at various cortical and subcortical locations in the medial premotor system, but not the lateral premotor system, probably give rise to UB. Archibald et al. (2001, p. 129; inspired by Goldberg, 1985) 
hypothesize that the medial premotor system, which is characterized by internally-driven behavior as well as by the inhibition and modulation of stimulus-driven behavior, functions upstream from and exerts control over the lateral premotor system.

\section{Cortico-striatal connectivity and the neural context of striatal activity}

When motor skills become automated, the relative contribution of subcortical structures, such as the basal ganglia and cerebellum, versus cortical structures increases (Edelman \& Tononi, 2000). (Notwithstanding this change in the relative contribution of brain areas, the neural basis of a skillful act involves the contribution of a widely distributed network of brain activity.) Here I would like to discuss the cortico-striatal connectivity because the abundant connections between the prefrontal cortex and the striatum may contribute to the rich contextual background (at the neural level) that is required for adequate action (Goldberg, 1985). I will discuss the implications for our understanding of UB and link it to Freeman's work on neurodynamics.

\subsection{Introduction}

Anatomically the cortico-striatal tracts are organized along a rostro-caudal axis (Lehericy et al., 2004b; Alexander et al., 1986). These parallel circuits support distinct behavioral functionalities. For example, distinct striatal regions support visually guided limb movement selection, preparation and execution (Gerardin et al., 2004). Situations with a more cognitive aspect such as value or reward involve the more rostral cortico-striatal 
circuits (Gerardin et al., 2004). A study on learning suggests that the pre-SMA and the caudate nucleus may not just be well connected but form a unified functional loop (Boettiger \& D’Esposito, 2005, p. 2729).

Importantly, the associative striatum (anterior dorsal striatum) is, just like the preSMA/ACC, very well connected with the prefrontal cortex (Lehericy et al., 2004a). A diffusion tensor tract tracing study in humans by Lehericy et al. (2004a) shows that fibers associated with the head of the caudate nucleus are directed towards the medial frontal cortex (rostral to the pre-SMA), to the dorsal prefrontal cortex (Broadman area, henceforth $B A 9$ and 46), the ventral prefrontal cortex (BA 45 and 47), the frontal pole (BA 10) and the mesencephalon.

The anterior putamen has connections with the pre-SMA, lateral premotor cortex (BA 6 and 8), ventrolateral prefrontal cortex (BA 45 and 47), dorsolateral prefrontal cortex (BA 9 and 46) and the mesencephalon (Lehericy et al., 2004a). Overall the head of the caudate appears to be connected to a host of prefrontal areas somewhat rostral to those connected with the anterior putamen (Lehericy et al. 2004a, pp. 524-525; for more on the rostro-caudal organization of the cortico-striatal tracts see Lehericy et al., 2004b). Given these data on its massive prefrontal connections, it seems likely that the rostral caudate nucleus receives convergent input from various prefrontal areas. At the neural level, such a rich contextual background is probably crucial for the caudate's proper contribution to the performance of appropriate or valuable actions. 


\subsection{The link with UB}

This pattern of connectivity suggests a potential answer to the question of why damage to the caudate nucleus is relatively often encountered in patients with utilization behavior. As a result of its anatomical interconnectedness with the pre-SMA/dACC (probably forming an integrated cortico-striatal functional unity, the unified functional loop mentioned above), rostral caudate dysfunction might perhaps lead to utilization behavior because it disturbs the functionality of this ACC-circuit. ${ }^{17}$ Moreover, integrated functioning of this circuit would imply that normally the generation of actions worth doing (Rushworth et al., 2004) is not a task of just the medial prefrontal cortex or just the caudate nucleus (or just the dorsal striatum), but is a function which crucially engages both the pre-SMA/ACC and the dorsal striatum as well as the other subcortical areas of the circuit concerned. This would mean that damage to the associative striatum can impair this function.

Since in the end I am interested in understanding our normal behavioral regulation and its reliable attunement to the particular and complex situation, it is important to know that many prefrontal areas project on the caudate. By means of these projections we understand somewhat better how it is possible that the caudate's cortico-striatal loops are normally able to contribute to the endogeneous generation of actions worth doing; to adequate performances. 


\subsection{Zooming out: The link with Freeman's work}

With respect to the bigger picture of the self-organized emergence of endogeneous intentions to act, it is interesting to note that, according to Teking and Cummings (2006, p. 649), the ACC-circuit receives open afferents from the hippocampus and the entorhinal cortex. According to Freeman (2000a, pp. 100-05), the entorhinal cortex plays (in close cooperation with the hippocampus) a crucial role in the integration of sensory information from various areas (multisensory convergence, figure-ground separation/gestalt generation) and in the construction and maintenance of a landscape of

attractors. ${ }^{18}$ Importantly, according to Freeman, an odorant-related macroscopic neural activity pattern is best understood not as a representation of an odor but as a pattern corresponding to a perceived affordance, such as 'smell-of-food-to-be-eaten' or 'smellof-predator-to-run-away-from’ (Freeman, 2000a, p. 89). Dreyfus summarizes Freeman’s (2000a) position in a way that may make it easier to see the relationship between neurodynamics and the field of affordances:

'[An] attractor does not represent, say, a carrot, or a carrot scent, or even what to do with a carrot. Rather, the brain's current state is the result of the sum of the animal's past experiences with carrots, and this state is directly coupled with or resonates to the experience - smells like a carrot to be eaten now. [...] Presumably the whole constantly updated pattern of attractors [the attractor landscape, ER] is correlated with the animal's experience of encountering changing significances in its world.' (Dreyfus, 2007d, pp. 3-4). 
In other words, according to Freeman and Dreyfus, the brain's macroscopic activity pattern relates dynamically to the significances (plural) in the given particular situation; or in my own words, to the field of relevant affordances. Assuming Freeman's (2000a) analysis is right, this kind of holism or integrated functioning at the neural level is the core of the (body- and world-coupled) brain's contribution to context-sensitivity.

Moreover, according to Freeman (2000b), 'emotion is essential to all intentional behaviors'. He suggests that the best starting point for the purpose of the analysis of intentional behavior is the self-organization of neural activity in the limbic system of the whole acting organism (Freeman, 2000a, p. 95, p. 105). These limbic system neurodynamics, in which the entorhinal cortex plays a crucial role, 'invite' the cooperation of prefrontal areas (Freeman, 2000a, p. 105). Limbic connections with the brainstem are crucial for release of the many types of neuromodulators, which at once affect large areas of the brain and contribute to the rapid arising of emotion and

intentional action (Freeman, 2000a, p. 107).${ }^{19}$ The neuromodulatory chemicals also have an impact on the sensory system's sensitivity to some stimuli rather than others (see section 5 on preafference below).

\subsection{Conclusions utilization behavior}

To conclude, frontal-subcortical circuits are a crucial part of the medial premotor system and contribute to the self-organization of action that is attuned to the particular and complex situational context. In utilization behavior parts of this same medial system for endogeneous action have been damaged. In contrast to akinetic mutism patients, 
however, UB-patients still show responsiveness to the environment, namely to irrelevant affordances.

What do we learn about normal behavior from utilization behavior? We have to be careful here, because the relationship between the pathological and normal is not straightforward. A justified conclusion seems to be that this disorder suggests that perceived familiar objects influence us at the neural level (and potentially at the behavioral level). Here we encounter a likely link with Merleau-Ponty's (2002/1945) descriptions of objects affecting us (Rietveld, 2008a). Normally in familiar domains we are able to respond appropriately to perceived opportunities for action in the environment. By showing how much can go wrong in the adjustment to the situational context (and to its various dimensions), UB makes clear that our normal everyday comportment is very well attuned to our personal interests and social context.

\section{Freeman on preafference in normal behavior: self-organized sensitivity to relevance}

\subsection{Introduction}

It is important to see that, in theory at least, a UB-patient's unlesioned lateral premotor system could still contribute to the generation of appropriate actions if only it were responsive to relevant rather than irrelevant affordances. In that case, the action would be fully stimulus-driven (and not endogeneously-driven), yet adequate. In this section I will use Walter Freeman's work on preafference to explain why it is likely that a lesion of the medial premotor system disturbs the sensory-system's sensitivity to relevance. This 
clarifies one of the ways in which the medial system functions 'upstream from' the lateral system (as was suggested, but not explained, by Archibald et al., 2001, p. 129). In short, preafference helps to understand why normally the stimulus-driven system is sensitive to one stimulus rather than another. I will also discuss the implications for Wheeler's account.

\subsection{Preafference}

In Dreyfus' sub-personal account, thanks to prior experience, reliable sensitivities have become rooted in developed neural connections. ${ }^{20}$ But the emerging self-organized cell assemblies should be understood as dynamic elements of a brain-body-environment system: they can be primed by the environment as well as by the current concerns of the organism (Dreyfus, 2008; Freeman, 2000a). How could priming by our current needs work? Below we will see that Freeman's notion of preafference sheds some light on this.

Dreyfus gives the following example of a context-specific attunement of sensitivities:

'So if a male animal has just eaten and is ready to mate, the gain [the selforganized sensitivity to input, ER] is turned down on the cell assemblies responsive to food smells, and turned up on female smells. Thus, from the start the cell assemblies are not just passive receivers of meaningless input from the 
universe but, on the basis of past experience, are tuned to respond to what is significant to the animal given its arousal state.' (Dreyfus, 2008, p. 350).

It is not only humans (and animals) who respond directly to the significant aspects of the situation. After learning their neural cell assemblies respond to significance as well. This neural responsiveness to significance may sound like a category mistake, but probably is not. What Dreyfus presumably wants to say is that organisms as a whole are responsive to significance, but that a cell assembly is an integrated part of this organism as a whole (and of the brain-body-environment system). This denies that responsiveness to significance can be reduced to this neural cell assembly or that reference to this cell assembly is all there is to say about responsiveness to significance. On the contrary, these cell assemblies are part of one integrated self-organizing dynamic system made up by brain, body and environment and therefore directly coupled to both the (natural and social) environment and the state of the living organism as a whole. We could see detection of relevance as the operation of embodied second nature. The individual is a relevance-sensitive body that develops over time. Thanks to upbringing and experience, our sensitivity to significance has become second nature.

Inspired by Freeman (2000a), Dreyfus (2008, pp. 353-54) speculates that at the neural level a complex of attractors contributes to the situation-specific attunement. The individual's landscape of attractors, the continually shifting sensitivity to the situation's affordances, is the result of past training in, and experience with, the environment. After learning his or her neural cell assemblies determine the attractor landscape. This neural network is now tuned to resonate to current global significance. According to Walter Freeman (2000a, p. 22, cf. pp. 77-80), the holistic character of the repertoire of attractors 
can be observed at the neural level when an animal learns to discriminate a new significant class of stimuli (for instance a new odor). Interestingly, this has an impact on other attractors that were not directly involved in the learning process.

Concerning the issue of priming sensory areas by the individual's needs, it is of crucial importance to see that before a stimulus arrives the organism's perceptual system is already selectively sensitive to relevant stimuli, and the individual specifically sensitive to some affordances rather than others. When the perceptual process of online tuning to relevant stimuli works smoothly, for example in skillful absorbed coping, even stimulusdriven action is to some extent an instance of endogeneously-driven behavior, because the sensory system ignores irrelevant stimuli and contributes to the perception of currently relevant stimuli. Our rapid unreflective responsiveness to affordances in absorbed coping probably has this relevance-tuned perception-action loop at its core. Walter Freeman's (2000a) work on preafference (Kay \& Freeman, 1998) sheds some more light on this self-organized or self-generated sensitivity to relevance at the neural level.

Anatomically the sensory system is bidirectionally connected to other parts of the brain. This allows activity from various parts of the brain, in particular from the limbic system and from the global self-organized neural activity patterns that underlie the generation of actions (and related efference copies) to prime the sensory cortex in a way that increases the likelihood of the detection of currently relevant smells, sights, sounds, or tastes (Freeman, 2000a, p. 33, p. 108; Kay \& Freeman, 1998). Using the language of neurodynamics, Freeman describes this sensory preparation thus: 
'Preafference provides an order parameter that shapes the attractor landscapes, making it easier to capture $[\ldots]$ desired stimuli by enlarging or deepening the basins of their attractors.' (Freeman, 2000a, p. 108).

So global (as well as limbic, Kay \& Freeman, 1998) neural cell assemblies, which underlie endogenously generated intentions to act, can, even before the arrival of the desired stimulus, have some specific impact on the tuning of sensory areas (the olfactory bulb in Kay \& Freeman, 1998).

Switching to the conceptual framework of cognitive neuroscience, ${ }^{21}$ Freeman (2000a) also describes this process as tuning the sensory area's receptiveness. Selfgenerated or endogeneous activity spills-over to the anatomically connected sensory system and primes it (for example the olfactory bulb). It is important that such tuning of populations of cortical neurons is not the non-specific increase in sensitivity generated by a higher level of arousal (Freeman, 2000a, p. 93), but a tuning for specific classes of input (for instance odor-specific tuning, or tuning for a specific type of predator) (Freeman, 2000a, p. 74, pp. 92-93, p. 133). Without non-specific arousal the sensory area in general is insensitive, but without preafference by endogeneously generated activity, its directed sensitivity to particular types of relevance is reduced and the likelihood of perceiving (and responding to) irrelevant stimuli increases.

To sum up, preafference contributes to the organism's directed sensitivity to relevance. An odorant-related self-organized neural activity pattern (cell assembly) is best understood not as a representation of an odor but as a pattern coupled to an affordance (Freeman, 2000a, p. 89). We can say that preafference tunes the perceptual system for the detection of relevant affordances. In other words, at the neural level, the 
individual's endogeneously generated activity primes the sensory system for the detection of affordances worth acting on.

\subsection{Implications of preafference for understanding utilization behavior}

The notion of preafference sheds important light on utilization behavior because it suggests that the irrelevance of the patients' stimulus-driven actions may in part be a consequence of missing preafferent input due to an absence of limbic and cortical activity related to endogenously-driven action. This is in line with the suggestion by Rudd et al. (1998, p. 296) that the internally driven control of attention to stimuli could be disturbed

in $\mathrm{UB}^{22}$ Normally, the reciprocal connections between the sensory areas, the limbic system and the prefrontal cortex make it possible that the emergence of an endogeneously generated (motor) intention dynamically tunes, through preafference, the sensitivity of the various sensory areas in a coordinated way. The affective flatness and loss of voluntary or self-generated action manifested by UB-patients suggest that the neural process that contributes to preafference is likely to be disturbed. In other words, a lesion of the medial premotor system not only disinhibits the lateral premotor system, but also undermines the neural tuning for and detection of relevance.

It is important to note that it is certainly not the case that preafference does all the explanatory work in my account of UB. It is the bilateral lesion of the medial premotor system that does, but such a lesion can have multiple effects and one of these is a disturbance of preafference. Others -at the neural level- are a loss of the normal modulation by the medial premotor system of stimulus driven activity generated by the lateral premotor system and dysinhibition of this latter neural system. As mentioned in 
the introduction to this section, I have included a discussion of preafference to shed light on what might be seen as a technical detail, namely, that in theory a UB-patient's unlesioned lateral premotor system could still contribute to the generation of appropriate actions if only it were responsive to relevant rather than irrelevant affordances. Along the way we have seen that preafference clarifies one (but not all!) of the ways in which the medial system functions 'upstream from' the lateral system, namely by tuning the sensitivity of other areas such as the sensory ones.

\subsection{Implications for Wheeler's account}

How could this discussion of UB and preafference be related to Wheeler's (2008) discussion of situated special purpose adaptive couplings (SPACs)? Although Wheeler holds that according to him humans are 'collections of special purpose subsystems' (Wheeler, 2005, p. 278) and, moreover, that the relevant mechanisms can be understood as learned in socio-cultural contexts (now embodied as 'installed routines', Wheeler, 2008, p. 347), he is, unfortunately, not explicit about the specific neural mechanisms that could underlie human 'intra-context' sensitivity to relevance. Given that we know from cognitive neuroscience (for example Rizzolatti \& Sinigaglia, 2008; cf. Rizzolatti \& Luppino, 2001) that perceived objects do indeed trigger neural activity (in the lateral premotor system) and action readiness in ways that are sensitive to the particular object affordances (which in turn depend on the individual's skills or routines and the object in a limited- context), presumably that lateral premotor system would be a plausible candidate for the bottom-up (or stimulus-driven) mechanism Wheeler has in mind when he describes SPACs. 
However, preafference shows that the triggering of SPACs (which, at the neural level of description, is a stimulus-driven mechanism, that is presumably a lateral premotor system-related mechanism) presupposes the proper functioning of the medial frontal system that determines the sensitivity of the sensory system; tunes it to respond to what is currently significant to the individual (cf. Dreyfus, 2008, p. 350). Importantly, this modulation of the system's sensitivity is something that normally happens before the stimulus is picked up. In other words, the proper functioning of the lateral premotor system, which Wheeler might be tempted to associate with special-purpose adaptive couplings, is not independent of the medial premotor system, but rather dependent on it. Akinetic mutism shows even more clearly that a collection of SPACs cannot function adequately without proper functioning of the medial premotor system. In this neurological condition (Devinsky et al., 1995), large bilateral lesions of the medial frontal cortex (which leave the lateral premotor cortext unlesioned) completely undermine the individual's responsiveness to relevance (these patients show a total absence of initiative and neither speak nor act). So even though the lateral premotor cortex, which presumably would be the neural basis of Wheeler's SPACs, is unaffected in akinetic mutism, responsiveness to relevant affordances is severely disturbed in the case of these patients. Responsiveness to relevance requires more than just a collection of SPACs rooted in the lateral premotor cortex. 


\section{The irrelevance of 'intra-context sensitivity to relevance'}

\subsection{Introduction}

The frame problem has a basic (and unmysterious, see Rietveld 2008c) normative aspect. Recall that it is about adequate sensitivity to context-dependent relevance. Given this normative aspect, the frame problem is not to be located primarily at a purely causal level of description (for instance the neural level), but at the level of the individual as a whole in his or her natural and social environment. In his most recent response to Hubert Dreyfus (2008), Michael Wheeler (2008, p. 323) has suggested that the frame problem is 'a two-headed beast'. He distinguishes between the 'intra-context' frame problem and the 'inter-context' frame problem. I will argue that this distinction does not make much sense for understanding normal behavior, because in cases of human (and animal) online intelligence, sensitivity to real relevance is not a feature of responsiveness to some limited part of the context (as 'intra-contextual' sensitivity to relevance would imply) but of responsiveness to the individual's full particular and complex situation. Since we tend to take this for granted, the contrast provided by the pathological case of utilization behavior helps to illustrate this point about normal behavior. Patients with UB manifest what Wheeler would call 'intra-context' sensitivity to relevance (they act in technically adequate ways). Yet, given their full particular situation (or context) their actions are inappropriate and we can characterize their behavior as form of responsiveness to irrelevant affordances. Let me elaborate on this. 


\subsection{Wheeler's notion of intra-context sensitivity to relevance}

What does Wheeler (2008, p. 346) mean by 'intra-context sensitivity to relevance'? Wheeler characterizes this feature of online intelligence as 'the production of behavioral responses that are appropriately keyed to the context of activity in which the agent finds itself' (Wheeler, 2005, p. 231, my italics). His prototypical and illuminating example of this is the female cricket's selective responsiveness to the male cricket's auditory signal. The core of his causal explanation of this selective responsiveness is traced back to what Wheeler calls a 'special-purpose adaptive coupling' (Wheeler, 2008, p. 334):

'In my view, situated special-purpose adaptive couplings may make it intelligible to us how it is that unmysterious causal processes, such as those realized subagentially in brains, can give rise to the agential level phenomenon of thrownness [i.e. of being always already embedded in a context] ... [T] he situated special-purpose adaptive coupling that constitutes the cricket phonotaxis mechanism works correctly only in the presence of the right, contextually relevant input [that is the male cricket's auditory signal, ER]' (Wheeler, 2008, pp. 334-35).

So according to Wheeler the contextually triggered activity of such a 'special-purpose adaptive coupling' (SPAC) is what underlies our appropriate responsiveness to a given context. Not only in the case of humans (see section 5), but also in the case of crickets it makes sense to investigate the way neurons contribute to a SPAC. ${ }^{23}$ 


\subsection{A problem for Wheeler: real relevance}

However, the problem is that for 'intra-contextual' activity to be responsive to what is really relevant in the situation and to be a manifestation of online intelligence, it cannot ignore the broader context. For a female cricket, mating is not the thing to do when she is

about to starve of hunger or when a predator is arriving on the scene. The intelligent thing to do would be to give priority to a possibility for action outside the narrow intra-context of the mating situation, that is to the broader context. To respond intelligently to the full particular situation she would need 'inter-context' sensitivity to relevance, to use Wheeler's term. Therefore, I would like to suggest that real relevance is something that is relative to the whole individual's full particular and complex situation, and not relative to a mere 'intra-context'.

As we have seen, a patient with utilization behavior (Lhermitte, 1986) may undress on seeing a bed in a way that is technically correct (responding to what normally used to be relevant to him). Another patient may make the bed in a technically correct way, responding to what normally was relevant to her. The intentional arc (MerleauPonty, 2002/1945; Dreyfus, 2008) makes intelligible that they are responsive to different solicitations. A history of past experience with beds feeds back into the perceived situation they are now responsive to. Thanks to this past experience they act in technically adequate ways: presumably getting undressed in the normal way or making the bed as usual. In both cases Wheeler would presumably speak about culturally 'installed routines'.

Yet, given the broader context (being shown around in someone else's house) both patients' responses turn out to be responses to irrelevant affordances rather than 
relevant affordances. A relevant possibility for action could for instance be saying something nice about an aspect of the other person's bedroom. Given the context as a whole (the particular and complex real life situation) both actions (getting in the bed and making the bed) are inappropriate and both patients respond to irrelevant affordances.

Note that it is precisely the fact that UB is a pathological case that makes it possible to distinguish between technically correct and contextually incorrect behavior. In normal behavior these two aspects do not come apart but are seamlessly integrated/intertwined. For a normal person making the bed in one's own house versus in one's doctor's house are two very different activities experientially. It is part of the pathology of UB that the patient's sensitivity to this has disappeared.

\subsection{Response to a possible objection}

Now Wheeler could of course object by saying that not only the state of the bed (made or not made) should be included in the SPAC's intra-context, but that, on top of that, also the fact that a bed is in someone else's house should be seen as part of the intra context.

But, we could ask Wheeler, what should we include and what not? Should the intra-context include whose bedroom it is (the neurologist's, the hospital's or one's own)? Should it include the patient's needs (for instance does he or she urgently have to go to the toilet or not, is he of she tired or not)? Should it include whether the building is on fire or not? Making a bed surely isn't an adequate thing to do when the house is on fire. Etc., etc.

More importantly, by extending the 'intra-context' of the bed-SPAC in such a way that it would include all of the above, in the end it seems Wheeler will end up with 
one overall situated adaptive coupling to the complex particular situation as a whole. However, pulling this string of broadening the 'intra-context' does not help Wheeler, because it amounts to requiring the kind of global holism that 'intra-context sensitivity to relevance' by definition lacks.

To make the same point differently, we can perhaps say that what Wheeler (2005, p. 279 , my italics) calls 'the reevaluation what the task might be' is not something that happens every now and then, for instance when a task is finished, but is a continuous (unreflective) process that puts whatever one is doing right now in perspective (cf. Varela, 1999/1992, pp. 55-56). It is a crucial aspect of bodily (or motor) intentionality in on-line cognition that it is open to soliciting possibilities for action on the horizon; it is situated in a field of relevant affordances (Merleau-Ponty, 2002/1945; Dreyfus, 2007c; Rietveld, 2004, 2008a/b). From this point of view, too, it becomes completely unclear what is still 'intra' about the context of the SPAC. In coping with the unmade bed in a way that does justice to its real situational relevance, the individual ends up coping with exactly the same full and particular (or 'inter') context that Wheeler had wanted to reserve for context switching.

In sum, the real relevance of what at first sight may seem to be an 'intra-context' affordance depends ultimately on exactly the same context as the decision of what to do next (continue with the current activity or switch to another task), namely the individual's full and particular situation. If the frame problem is about adequate sensitivity to contextdependent relevance, then we should take as our starting point for understanding it the level of the whole active individual in what Aristotle (NE 1142a25) calls the 'ultimate particular thing', namely the concrete situation (McDowell, 2007a, p. 340). I will end this final section with a quote from McDowell that illustrates, in a way that should appeal to 
Heideggerians since it sheds light on the kind of beings that we are, this need for adequate sensitivity to a very rich as well as a highly specific situation:

Heidegger depicts Aristotelian practical wisdom [phronēsis, ER] as, in Dreyfus' words, "a kind of understanding that makes possible an immediate response to the full concrete situation". Dreyfus quotes Heidegger saying this: "[The phronimos...] is determined by his situation in the largest sense. $[\ldots]$ The circumstances, the givens, the times and the people vary. The meaning of the action $[\ldots]$ varies as well $[\ldots]$. It is precisely the achievement of phronēsis to disclose the [individual] as acting now in the full situation within which he acts."

But that is just how I [McDowell, ER] understand Aristotelian practical wisdom. (McDowell, 2007, p. 340, citing Dreyfus, 2005, p. 51, which contains a quote from Heidegger, 1997, p. 101; Dreyfus' italics). ${ }^{24}$

\section{Conclusion}

My main conclusion is that the frame problem is indeed a 'fearsome beast' (Wheerler, 2005 , p. 249), but not a two-headed one. Sensitivity to the full particular and complex situation is more important for explaining normal online cognition than any 'intracontext' sensitivity. What Wheeler calls 'intra-context' sensitivity to relevance is an adequate sensitivity to real relevance only when the individual's full particular situation is taken into account. For normal, real-life situations of humans and animals this 
undermines the relevance of Wheeler's (2008) distinction between the intra-context and inter-context frame problem.

Since Wheeler has already agreed with Dreyfus that continuous reciprocal causation $(\mathrm{CRC}$, which can for instance be modeled for instance by a Freeman-style neurodynamic approach) underlies contextual sensitivity ('inter-context' switching) on broader scales, I think that, given my conclusion, he should accept that in the end CRC turns out to be the mechanical basis of all online sensitivity to real context-dependent relevance, not just of inter-context sensitivity.

In a Freeman-style account, the brain's macroscopic activity pattern is not related to just one affordance, but coupled dynamically to a field of relevant affordances in the concrete situation (section 4.3). The positive alternative, which Wheeler rightly urges that Heideggerian cognitive science should develop, could find a proper starting point here. Action-oriented representations and special purpose adaptive couplings are far less important for explaining online intelligence than Wheeler (2005) implied.

The priority of adequate sensitivity to the full situation's real relevance (and CRC as its most basic causal mechanism) makes also clear that Wheeler's (2008, p. 346) claim that continuous reciprocal causation and situated special purpose adaptive couplings are equiprimordial is incorrect. Non-representational continuous reciprocal causation is not only more basic for dissolving the frame problem than action oriented representations, it is more basic than situated special purpose adaptive couplings as well.

One aim of this paper was to establish a methodological point (see Klaassen et al., 2010). The fact that continuous reciprocal causation is the crucial causal mechanism for explaining sensitivity to real relevance, does not imply that we should study the phenomenon of online cognition only by means of the methods from neurodynamics. On 
the contrary, we have seen that there is a lot to be learned about central phenomena (such as responsiveness to a single affordance and, more fundamentally, to a field of relevant affordances) by treating the insights from various disciplines (philosophy, phenomenology, neurology, neuropsychology, cognitive neuroscience, etc.) as complementary.

\section{Acknowledgements}

I would like to thank Hubert Dreyfus, Paul Eslinger, Walter Freeman, Janna van Grunsven, Julian Kiverstein, Kranti Saran, and Martin Stokhof for feedback on an earlier version of this paper. I did part of the research for this paper during my stay as a Fellow in Philosophy at Harvard University and I thank Sean Kelly for inviting me and for his comments. My research visit was funded by 'Netherlands Organisation for Scientific Research' (NWO). I would like to express my gratitude for awarding this Rubicon grant.

\section{References}

Alexander, G.E., Delong, M.R. \& Strick, P.L., 1986. Parallel organization of functionally segregated circuits linking basal ganglia and cortex. Annual Review of Neuroscience, 9, pp. $357-81$.

Archibald, S., Mateer, C. \& Kerns, K., 2001. Utilization behavior: Clinical manifestations and neurological mechanisms. Neuropsychology Review, 11, pp. 117-30. 
Aristotle, 1985. Nicomachean Ethics, trans. Irwin, T. (Indianapolis: Hackett Publishing Company).

Benke, T., Delazer, M., Bartha, L. \& Auer, A., 2003. Basal ganglia lesions and the theory of fronto-subcortical loops: Neuropsychological findings in two patients with left caudate lesions. Neurocase, 9 (1), pp. 70-85.

Bhatia, K.P. \& Marsden, C.D., 1994. The behavioural and motor consequences of focal lesions of the basal ganglia in man. Brain, 117, pp. 859-76.

Boccardi, E., Della Sala, S., Motto, C. \& Spinnler, H., 2002. Utilisation behaviour consequent to bilateral SMA softening. Cortex, 38, pp. 289-308.

Boettiger, C.A. \& D’Esposito, M., 2005. Frontal networks for learning and executing arbitrary stimulus-response associations. The Journal of Neuroscience, 25, pp. 2723-32.

Bressler, S.L. \& Kelso, J.A.S., 2001. Cortical coordination dynamics and cognition. Trends in Cognitive Sciences, 5, pp. 26-36.

Chemero, A., 2003. An outline of a theory of affordances, Ecological Psychology, 15 (2), pp. 181-95. 
Colombetti, G., 2005. Appraising valence. Journal of Consciousness Studies, 12, pp. 10326.

Cairns, H., Oldfield, R.C., Pennybacker, J.B. \& Whitteridge, D., 1941. Akinetic mutism with an epidermoid cyst of the $3^{\text {rd }}$ ventricle. Brain, 64, pp. 273-90.

Devinsky, O., Morrell, M.J. \& Vogt, B.A., 1995. Contributions of anterior cingulate cortex to behaviour. Brain, 118 (1), pp. 279-306.

Dreyfus, H.L., 2000. Responses. In Malpas, J. \& Wrathall, M.A., eds. Heidegger, Coping, and Cognitive Science: essays in honor of Hubert L. Dreyfus. Cambridge, MA: MIT Press, pp. 337-44.

Dreyfus, H.L., 2005. Overcoming the myth of the mental: How philosophers can profit from the phenomenology of everyday expertise (APA Pacific Division Presidential Address 2005), Proceedings and Addresses of the American Philosophical Association, 79 (2), pp. 47-65.

Dreyfus, H.L., 2007a. The return of the myth of the mental. Inquiry, 50 (4), pp. 352-65.

Dreyfus, H.L., 2007b. Response to McDowell. Inquiry, 50 (4), pp. 371-77.

Dreyfus, H.L., 2007c. Reply to Romdenh-Romluc. In Baldwin, T., ed. Reading MerleauPonty: On Phenomenology of Perception. New York: Routledge, pp. 59-69. 
Dreyfus, H.L., 2007d. Walter Freeman's Merleau-Pontian neurodynamics. Paper presented at the Conference on Brain Network Dynamics, UC Berkeley, January 26-27, 2007. Online January 4, 2007:

www.archive.org/details/Brain_Network_Dynamics_2007-15-Hubert_Dreyfus.

Dreyfus, H.L., 2008. Why Heideggerian AI failed and how fixing it would require making it more Heideggerian. In Husbands, P., Holland, O. and Wheeler, M., eds. The Mechanical Mind in History. Cambridge, MA: MIT Press, pp. 331-71.

Dreyfus, H.L. \& Kelly, S.D., 2007. Heterophenomenology: Heavy-handed sleight-ofhand. Phenomenology and the Cognitive Sciences, 6, pp. 45-55.

Edelman, G.M. \& Tononi, G., 2000. Consciousness: How Matter Becomes Imagination. London: Penguin.

Eslinger, P., 2002. The anatomic basis of utilisation behaviour: A shift from frontalparietal to intra-frontal mechanisms. Cortex, 38, pp. 273-76.

Freeman, W.J., 2000a. How Brains Make Up Their Minds. New York: Columbia University Press.

Freeman, W.J., 2000b. Emotion is essential to all intentional behaviours. In Lewis, M.D. \& Granic, I., eds. Emotion, Development and Self-Organization: Dynamic Systems 
Approaches to Emotional Development. New York: Cambridge University Press, pp. 209-35.

Frijda, N.H., 1986. The Emotions. Cambridge, UK: Cambridge University Press.

Frijda, N.H., 2004. Emotions and action. In Manstead, A.S.R., Frijda, N.H. \& Fisher, A.H., eds. Feelings and Emotions: The Amsterdam Symposium. Cambridge, UK:

Cambridge University Press, pp. 158-73.

Frijda, N.H., 2007. The Laws of Emotion. Mahwah, NJ: Lawrence Erlbaum Associates, Inc.

Frijda N.H., 2010. Impulsive action and motivation. Biological Psychology. [xxxpages etc.]

Frijda, N.H., Manstead, A.S.R., \& Fisher, A.H., 2004. Epilogue: Feelings and emotions: Where do we stand? In Manstead, A.S.R., Frijda, N.H. \& Fisher, A.H., eds. Feelings and Emotions: The Amsterdam Symposium. Cambridge, UK: Cambridge University Press, pp. $455-67$.

Gerardin, E., et al., 2004. Distinct striatal regions support movement selection, preparation and execution. Neuroreport, 15, pp. 2327-31. 
Gibson, J.J., 1979. The ecological approach to visual perception. Boston: Houghton Lifflin.

Goldberg, G., 1985. Supplementary motor area structure and function: Review and hypotheses. Behavioral and Brain Science, 8, pp. 567-616.

Grezes, J. \& Decety, J., 2002. Does visual perception of object afford action? Evidence from a neuroimaging study. Neuropsychologia, 40, pp. 212-22.

Grezes, J., et al., 2003. Objects automatically potentiate action: An fMRI study of implicit processing. European Journal of Neuroscience, 17 (2), pp. 2735-40.

Haselager, W.F.G. and Van Rappard, J.F.H., 1998. Connectionism, Systematicity, and the Frame Problem. Minds and Machines, 8, pp. 161-79.

Heft, H., 2001. Ecological Psychology in Context: James Gibson, Roger Barker, and the Legacy of William James's Radical Empiricism. Hillsdale, NJ: Lawrence Erlbaum Associates.

Heidegger, M., 1996/1927. Being and Time (Macquarrie, J. \& Robinson, E., trans.). Oxford: Blackwell Publishing.

Heidegger, M., 1997. Plato’s Sophist (Rojcewicz, R. \& Schuwer, A., trans.). Bloomington: Indiana University Press. 
Kay, L.M. \& Freeman, W.J., 1998. Bidirectional processing in the olfactory-limbic axis during olfactory behavior. Behavioral Neuroscience, 112 (3), pp. 541-53.

Klaassen, P., Rietveld, E \& Topal, J., 2010. Inviting complementary perspectives on situated normativity in everyday life. Phenomenology \& The Cognitive Sciences, 9, pp. 53-73.

Koffka, K., 1935. Principles of Gestalt Psychology. London: Lund Humphries.

Lehericy, S., et al., 2004a. Diffusion tensor fiber tracking shows distinct corticostriatal circuits in humans. Annals of Neurology, 55, pp. 522-29.

Lehericy, S., et al., 2004b. 3-D diffusion tensor axonal tracking shows distinct SMA and pre-SMA projectioins to human striatum. Cerebral Cortex, 14, pp. 1302-09.

Levy, N. \& Bayne, T., 2004. A will of one's own: Consciousness, control, and character. International Journal of Law and Psychiatry, 27, pp. 459-70.

Levy, R. \& Dubois, B., 2006. Apathy and the functional anatomy of the prefrontal cortexbasal ganglia circuits. Cerebral Cortex, pp. 916-28.

Lewin, K., 1935. A Dynamic Theory of Personality: Selected Papers (D.K. Adams, D.K. \& Zener, K.E., trans.). New York: McGraw-Hill. 
Lhermitte, F., 1983. 'Utilization behaviour' and its relation to lesions of the frontal lobes. Brain, 106, pp. 237-55.

Lhermitte, F., 1986. Human autonomy and the frontal lobes. Part II: Patient behavior in complex and social situations: The 'environmental dependency syndrome'. Annals of Neurology, 19, pp. 335-43.

Lhermitte, F., Pillon, B. \& Serdaru, M., 1986. Human autonomy and the frontal lobes. Part I: Imitation and utilization behavior. A neuropsychological study of 75 patients. Annals of Neurology, 19, pp. 326-34.

McDowell, J., 2007. What Myth? Inquiry, 50 (4), pp. 338-51.

Merleau-Ponty, M., 2002/1945. Phenomenology of Perception (Smith, C., trans.). London: Routledge.

Michaels, C.F., 2003. Affordances: Four points of debate. Ecological Psychology, 15 (2), pp. $135-48$.

Paus, T., 2001. Primate anterior cingulate cortex: Where motor control, drive and cognition interface. Nature Reviews Neuroscience, 2, pp. 417-24. 
Panksepp, J., 2005. On the embodied neural nature of core emotional affects. Journal of Consciousness Studies, 12 (8-10), pp. 158-84.

Rietveld, E.D.W., 2004. The Nature of Everyday Coping: Reinterpreting MerleauPonty's Phenomenology of Concrete Habitual Coping in the Light of Varela's Naturalization of Time-Consciousness. Paper presented at the ASSC-8 (Association for the Scientific Study of Consciousness) Conference, Antwerp, June 26-28, 2004.

Rietveld, E., 2008a. The skillful body as a concernful system of possible actions: Phenomena and neurodynamics. Theory \& Psychology, 18 (3), pp. 341-63.

Rietveld, E., 2008b. Unreflective Action. A Philosophical Contribution to Integrative Neuroscience. Dissertation University of Amsterdam. Amsterdam: ILLC-Dissertation Series DS-2008-05.

Rietveld, E., 2008c. Situated normativity: The normative aspect of embodied cognition in unreflective action. Mind, 117, pp. 973-1001.

Rietveld, E., 2010. McDowell and Dreyfus on Unreflective Action. Inquiry, 53 (2), pp. 183-207.

Rizzolatti, G. \& Luppino, G., 2001. The cortical motor system. Neuron, 31, pp. 889-901. 
Rizzolatti, G \& Sinigaglia, C., 2008. Mirrors in the Brain: How Our Minds Share Actions and Emotions. (Anderson, F., trans.) Oxford: Oxford University Press.

Rudd, R., et al., 1998. Stimulus relevance in eliciting utilisation behaviour: Case study in a patient with a caudate lesion. Cognitive Neuropsychiatry, 3 (4), pp. 287-98.

Rushworth, M.F., Walton, M.E., Kennerley, S.W. \& Bannerman, D.M., 2004. Action sets and decisions in the medial frontal cortex. Trends in Cognitive Sciences, 8, pp. 410-17.

Sanders, J.T., 1999. Affordances: An ecological approach to first philosophy. In Weiss, G. \& Haber, H.F., eds. Perspectives on Embodiment: The Intersections of Nature and Culture. London: Routledge, pp. 121-42.

Shallice, T., Burgess, P., Schon, F. \& Baxter, D.M., 1989. The origins of utilization behaviour. Brain, 112, pp. 1587-98.

Tekin, S. \& Cummings, J.L., 2002. Frontal-subcortical neuronal circuits and clinical neuropsychiatry: An update. Journal of Psychosomatic Research, 53, pp. 647-54.

Thelen, E. \& Smith, L.B., 1994. A Dynamic Systems Approach to the Development of Cognition and Action. Cambridge, MA: MIT Press.

Thompson, E., 2007. Mind in Life: Biology, Phenomenology, and the Sciences of Mind. Cambridge MA: The Belknap Press of Harvard University Press. 
Tsuda, I., 2001. Toward an interpretation of dynamic neural activity in term of chaotic dynamical systems. Behavioral and Brain Sciences, 24, pp. 793-847.

Van Grunsven, J., 2007. The Inevitable Body: An Inquiry into Various Approaches to Background and Intentionality. Unpublished Master thesis. University of Amsterdam, Faculty of Humanities, Department of Philosophy, Amsterdam.

Van Leeuwen, C., Steyvers, M. \& Nooter, M., 1997. Stability and intermittency in largescale coupled oscillator models for perceptual segmentation. Journal of Mathematical Psychology, 41, pp. 319-44.

Varela, F.J., 1999/1992. Ethical Know-How: Action, Wisdom, and Cognition. Stanford: Stanford University Press.

Wheeler, M., 2005. Reconstructing the Cognitive World: The Next Step. Cambridge, MA: MIT Press.

Wheeler, M., 2008. Cognition in Context: Phenomenology, Situated Robotics and the Frame Problem. International Journal of Philosophical Studies, 16 (3), pp. 323-49. 
Wrathall, M.A., 2000. Background practices, capacities, and Heideggerian disclosure. In Malpas, J. \& Wrathall, M.A., eds. Heidegger, Coping, and Cognitive Science: Essays in Honor of Hubert L. Dreyfus. Cambridge, MA: MIT Press, pp. 93-114. ${ }^{125}$

\footnotetext{
${ }^{1}$ There are various interpretations of the frame problem (Haselager and Van Rappard, 1998). I will focus on Wheeler's $(2005,2008)$ understanding of it, because this paper is a response to his claim that the frame problem is a 'two-headed beast' (Wheeler, 2008, p. 323).

${ }^{2}$ Continuous reciprocal causation closely resembles circular causality, a notion frequently used in the field of neurodynamics (see Freeman, 2000a).

${ }^{3}$ Wheeler writes: 'On the basis of our constantly honed background know-how, we respond directly to relevance, with context-bound entities soliciting or summoning us to act in ways shaped by our past experiences. And the capacity for flexible context-switching that lies at the heart of the inter-context frame problem is explained by the fact that I can be summoned not only by the present situation, but also by other situations that, because they have been relevant in the past, lie on the horizon of my experience [...]' (Wheeler, 2008, p. 344; he is referring to Dreyfus, 2008, 359).

${ }^{4}$ I would like to make explicit that I understand that the field of neurodynamics is in its early stages of development and in that sense limited. Yet even though for instance its precise link with neuroanatomical and neurophysiological research currently is still mostly unknown (but see Kay \& Freeman, 1998), neurodynamics does shed light on some important topics: for instance on functional brain integration and the phenomenon of metastability, on how rapid, self-organized switching between skillful actions is possible in unreflective action, and on the fact that affect generated by the perception of a significant object might perturb the system and increase the likelihood of the occurrence of such a switch (see Rietveld, 2008a). This latter example makes clear that what we would like to understand is not limited to neurodynamics but concerns the dynamics of the integrated brain-body-environment system.

${ }^{5}$ See Wheeler (2008). Dreyfus has not, or at least not yet, embraced this distinction. In section 6 I will argue that this distinction does not make much sense.
} 
${ }^{6}$ Wheeler writes: 'Now, I agree with Dreyfus that background coping is the phenomenological structure on the basis of which our context-sensitive activity is possible.' (Wheeler, 2008, p. 344).

${ }^{7}$ Both humans and non-human animals (for the sake of brevity animals) are responsive to affordances. McDowell, for instance, recently wrote: '[R]esponsiveness to affordances, necessarily bound up with embodied coping skills, is something we share with other animals.' (McDowell, 2007, p. 344). According to Sanders (1999) and Colombetti (2005) both the notions of valence (Lewin, 1935) and of affordance can be traced back to Kurt Lewin's (1935) term Aufforderungscharakter, which he had coined in 1926 (Sanders, 1999, p. 129). The Gestalt psychologist Koffka (1935) used the term demand-character to characterize Aufforderungscharakter (see Sanders, 1999, p. 129). As noted by Dreyfus and Kelly, 'Gibson himself did not emphasize the phenomenology of affordances, and indeed explicitly denied that affordances are defined in terms of their phenomenology in his arguments with the Gestaltists.' (Dreyfus and Kelly, 2007, p. 52; cf. Heft, 2001) See Sanders (1999) and Michaels (2003) for discussions on the issue of affordances and ontology, as I cannot go into this here.

${ }^{8}$ In the neurological condition utilization behavior, which is discussed below, we encounter examples of responsiveness to irrelevant affordances.

${ }^{9}$ A quote from Merleau-Ponty might illustrate this phenomenon of being affected by solicitations to act with a more marginal position in my field of relevant affordances: 'To see an object is either to have it on the fringe of the visual field and to be able to concentrate on it, or else respond to this summons by actually concentrating upon it.' (Merleau-Ponty, 2002/1945, p. 78, my italics).

${ }^{10}$ Janna van Grunsven (2007) introduced this term in an insightful discussion of Wrathall (2000) and Dreyfus (2000).

${ }^{11}$ Wrathall distinguishes between 1) mere capacities, 2) acquired capacities/abilities, and 3) readinesses: 'Within our set of abilities [...] and capacities, there will be some capacities which will be primed or ready according to the [...] structure of the situation. The distinction between a readiness and a capacity is not the same distinction as that between what I earlier called a 'mere' capacity and an ability. To see this point, imagine someone fluent in both German and English, but who has never had any exposure to Latin. We might say of this person that she has a (mere) capacity to understand Latin, but is able to understand German and English. In addition, when in the United States, she will ordinarily be ready to hear English, 
but not German. Indeed, if someone began speaking German to her, it might actually take a moment before she understood what was being said.' (Wrathall, 2000, pp. 112-113, my italics).

${ }^{12}$ This central role for readiness suggests that he might be willing to welcome Frijda's (1986) conceptual innovation of understanding the affective component as related to a change in action readiness.

${ }^{13}$ For readers familiar with the literature on mirror neurons and canonical neurons (for example Rizzolatti \& Sinigaglia, 2008; cf. Rizzoliatti \& Luppino, 2001), it might be helpful to keep in mind that both these types of neurons are located in the lateral premotor system. See also section 5.4 below.

${ }^{14}$ A patient who said he was no longer thirsty continued pouring and drinking water (Lhermitte, 1983; 1986, p. 342).

${ }^{15}$ Not all UB-patients reported in the literature had bilateral lesions. Rudd et al. (1998, p. 291) reported a case of a male patient who had a unilateral lesion in (the head of) the right caudate nucleus and showed incidental UB. However this patient also had considerable cerebral atrophy in mesial temporal structures. Various unilateral lesions were also reported by Lhermitte et al. (1986), but we do not know if these patients manifested induced or incidental utilization behavior. Given that Shallice et al. (1989) have argued convincingly that the test procedure for incidental (that means non-examiner-induced) utilization behavior is clearly better than that for induced UB, I prefer to focus as much as possible on the cases of incidental UB when drawing general conclusions about UB.

${ }^{16}$ Note that different nuclei of the thalamus are part of the lateral and of the medial premotor systems. Moreover, the term premotor system refers to a network of interconnected structures, both premotor and non-premotor structures (so this is not to suggest that, for instance, the cerebellum is a premotor structure). ${ }^{17}$ Given that the caudate nucleus participates in two more circuits (one originating from dorsolateral prefrontal cortex and one from the lateral orbitofrontal cortex, according to Tekin and Cummings, 2002, p. 651), a large lesion of it could perhaps even disturb the functioning of these circuits as well. That would also explain why Tekin and Cummings (2002, p. 651) associate these two circuits with UB. The lost functionality when a caudate circuit is lesioned involves various other types of executive function as well (Tekin \& Cummings, 2002).

${ }^{18}$ The notion attractor comes from dynamic systems theory and is a state (or set of states) toward which all nearby trajectories of the system converge over time. In analogy we can compare this 'to a ball rolling to 
the lowest point of a bowl, no matter where in the bowl it is originally dropped' (Freeman, 2000a, p. 55). However, it is important to mention that there are various types of attractors and that, unlike the ball that moves to the lowest point, certain inherently unstable systems can escape, that is to say, be attracted (or converge) only transiently. Such a system 'will always manage to free itself after a certain period' (Van Leeuwen, 1997, p. 321; cf. Tsuda, 2001; Bressler \& Kelso, 2001).

${ }^{19}$ Compare Wheeler's (2005, p. 268) remark on the importance of chemical dynamics for understanding biological adaptive behavior.

${ }^{20}$ Recall that Dreyfus' sub-personal account has been inspired by Walter Freeman's work in neurodynamics. Dreyfus summarizes Freeman's (2000a) perspective on adequate perception-action as follows: 'The animal, let's say, a rabbit sniffing a carrot, receives stimuli that, thanks to prior Hebbian learning, puts its olfactory bulb into a specific attractor basin $[\ldots]$ Significance is not stored as a memoryrepresentation nor an association. Rather the memory of significance is in the repertoire of attractors [which is dynamically and directly coupled with (or resonates to) gated stimuli (Dreyfus, personal communication, February 18, 2009)] -- the attractors themselves being the product of past experience. Once the stimulus has [activated a neural cell assembly coupled with eating now], the problem [...] is just how this eating is to be done.' (Dreyfus, 2008, p. 354, my italics). The olfactory bulb responds differentially, effectively selecting one activity rather than another (past learning has enhanced this ability to discriminate).

${ }^{21}$ As far as the methodology of embodied cognition is concerned, this use of two different vocabularies is in line with Thompson's (2007, p. 423) remark that for understanding brain activity, '[u]ltimately, it is the interplay between these heuristic categories [of both cognitive neuroscience and neurodynamics] within and across various explanatory contexts that is important [...]'. See also Panksepp: 'We need to consider how behaviour is controlled conjointly by neural and psychological causes. [...T]he psychological terms may be especially relevant for discussing the actions of large-scale neural networks' (Panksepp, 2005, p. 176). I agree with these two authors. The central role of continuous reciprocal causation (CRC) for explaining online intelligence does not at all imply that we should ignore the results and concepts of cognitive neuroscience and psychology. The insights from these fields can complement insights from philosophy and neurodynamics. 
${ }^{22}$ Note that Lhermitte et al.'s (1986, p. 330) behavioral test results suggest that UB-patients have a 'decrease in attention'.

${ }^{23}$ The following quotation shows that Wheeler's explanation of the cricket's selective responsiveness is primarily a neurobiological (rather than a computational) explanation: 'So how is it that the female tracks only the correct stimulus? The answer lies in the activation profiles of two interneurons (one connected to each of the female cricket's ears) that mediate between ear-drum response and motor behaviour. The decay rates of these interneurons are tightly coupled with the specific temporal pattern of the male's song, so that signals with the wrong temporal pattern will simply fail to produce the right motor-effects.' (Wheeler, 2008, p. 334).

${ }^{24}$ See Rietveld (2010) for a discussion of the Aristotelian common ground that Dreyfus and McDowell share. 